\title{
Experimental research on ADSCs-NCSS in wound repair
}

\author{
AI-JUN ZHANG ${ }^{1}$, TAO JIANG ${ }^{2},{\text { QIANG } \text { LI }^{3} \text {, PEI-SHENG JIN }}^{3}$ and QIAN TAN ${ }^{1}$ \\ ${ }^{1}$ Department of Burns and Plastic Surgery, The Drum Tower Clinical College of Nanjing Medical University, Nanjing, \\ Jiangsu 210008; ${ }^{2}$ Department of Burn and Plastic Surgery, Xuzhou Central Hospital, Xuzhou, Jiangsu 221000; \\ ${ }^{3}$ Department of Plastic Surgery, Affiliated Hospital of Xuzhou Medical University, Xuzhou, Jiangsu 221005, P.R. China
}

Received January 17, 2018; Accepted August 1, 2018

DOI: $10.3892 / \mathrm{etm} .2018 .6756$

\begin{abstract}
New collagen sponge scaffold (NCSS) combined with adipose-derived stem cells (ADSCs) in the repair of fullthickness skin wound in nude mice was investigated. Human ADSCs were extracted via enzyme digestion; NCSS materials were prepared using modified method; the tissue-engineered skin substitute was constructed using ADSCs combined with NCSS. Two $10 \mathrm{~mm}^{2}$ full-thickness skin wounds were designed on the back of 24 female nude mice, respectively. Mice were divided into 4 groups in the experiment: ADSCs-NCSS (group A), simple NCSS (group B), simple ADSCs (group C) and blank control (group D). The wound healing rates were observed at 3, 7, 10 and 14 days after operation, and specimens were taken at 1 and 2 weeks for histological detection and immunohistochemical cluster of differentiation 31 (CD31) vascular density detection, respectively. At 3 and 7 days after construction of new tissue-engineered skin substitute, the infiltration of ADSCs could be seen within NCSS. The wound healing rates at 7, 10 and 14 days after operation in group A were $(77.13 \pm 1.25 \%),(89.90 \pm 1.08 \%)$ and $(96.08 \pm 0.6 \%)$, respectively, which were significantly higher than those in groups B-D; the differences were statistically significant $(p<0.05)$. The detection of regenerated wound tissue thickness at 1 and 2 weeks after operation and CD31 vascular density at 1 week after operation showed that the vascular density in the wound in group A was significantly higher than those in other groups; the differences were statistically significant $(\mathrm{p}<0.05)$. After the transplantation of tissue-engineered skin constructed by human ADSCs combined with NCSS, the quality of wound healing in nude mice can be significantly improved, and the wound repair can be promoted.
\end{abstract}

Correspondence to: Dr Qian Tan, Department of Burns and Plastic Surgery, The Drum Tower Clinical College of Nanjing Medical University, 321 Zhongshan Road, Nanjing, Jiangsu 210008, P.R. China

E-mail: tan7vj@163.com

Key words: collagen scaffold, ADSCs, tissue-engineered skin, wound healing

\section{Introduction}

Skin is the largest organ in the human body, as well as an important tissue covering the body surface and protecting the internal organs. Inflammation, trauma, ulcers, and resection of large tumor on the body surface often lead to huge skin defects that are difficult to repair by themselves. The traditional repair method of large-area skin defects is autologous skin grafting; however, the autologous skin source of patients is often inadequate, there will be new incisions and scars will be left in the operative area, thus limiting its wide application in clinical practice. The construction and clinical application of tissue-engineered skin provide a new way and method for the repair of large-area skin defects. The seed cell and scaffold material are major factors in tissue engineering technique (1), the latter of which, as the transport carrier of seed cells, carries sufficient number of seed cells required for wound repair, ensuring the effective concentration of stem cells in wound repair process. A variety of scaffold materials have been widely used clinically, but no ideal scaffold materials have obtained satisfactory basic or clinical experimental results so far. At present, scaffold materials generally have such problems as low porosity, small cavity diameter, poor mechanical strength, high immunogenicity and too early degradation time or no degradation (2); therefore, many scholars have been exploring an ideal scaffold material that is safe, non-toxic, low in immunogenicity, moderate in degradation time, low in price and convenient in application $(3,4)$ for a long time. The new collagen sponge scaffold (NCSS) was successfully prepared via experimental research, and it was confirmed that NCSS had no obvious cytotoxicity, but a larger pore size and higher porosity, so it was suitable for cell adhesion and growth.

In this study, we tried to construct the tissue-engineered skin substitute using adipose-derived stem cells (ADSCs) combined with NCSS to repair the full-thickness skin defects in nude mice, and observe the effect of ADSCs-NCSS in wound repair.

\section{Materials and methods}

\section{Materials}

Main reagents. Low-glucose Dulbecco's modified Eagle's medium (DMEM-L) (Gibco; Thermo Fisher Scientific, Inc., Waltham, MA, USA); fetal bovine serum (FBS; Gibco, 
Melbourne, Australia); type I collagenase (Sigma-Aldirch; Merck KGaA, Darmstadt, Germany).

A total of 24 specific pathogen-free (SPF) nude mice (BALB/c-nunu type) with simple $\mathrm{T}$ cell deficiency, aged 3-5 weeks and weighing 18.2-21.1 g, were purchased from Laboratory Animal Center of Xuzhou Medical College (Xuzhou, China) and Shanghai SLAC Laboratory Animal Co., Ltd. (Shanghai, China) and qualified in animal quarantine.

Skin and adipose sources. Specimens were taken from surgical patients in the Department of Plastic Surgery and Thyroid and Breast Surgery of the Affiliated Hospital of Xuzhou Medical University. Patients aged 23-45 years signed the informed consent, those with infectious or skin lesions were excluded, and this study was approved by the Ethics Committee of the Drum Tower Clinical College of Nanjing Medical University (Nanjing, China).

\section{Methods}

Separation, acquisition and culture of human ADSCs. Human ADSCs were extracted according to the study of Zuk et al (5) and previous research (6,7): Under aseptic conditions, adipose tissues were taken, repeatedly washed with phosphatebuffered saline (PBS) containing the double antibody, cut into $1 \mathrm{~mm}^{3}$ pieces, followed by centrifugation at $960 \mathrm{xg}$ at $4^{\circ} \mathrm{C}$ in a $50 \mathrm{ml}$ centrifuge tube for $5 \mathrm{~min}$ twice. The upper-layer adipose tissues were retained, and incubated with $0.01 \%$ type I collagenase on a shaker at $37^{\circ} \mathrm{C}$ for $60 \mathrm{~min}$, followed by centrifugation at $2,010 \mathrm{x} \mathrm{g}$ at $4^{\circ} \mathrm{C}$ for $10 \mathrm{~min}$. The sediment was retained, resuspended using the double antibody-contained medium, and repeatedly filtered through a 200-mesh sieve, followed by centrifugation at $1,050 \mathrm{x}$ at $4^{\circ} \mathrm{C}$ for $5 \mathrm{~min}$. After the supernatant was discarded, cells were resuspended using the medium, and inoculated into a $25 \mathrm{~cm}^{2}$ perforated culture flask in an incubator with $5 \% \mathrm{CO}_{2}$ at $37^{\circ} \mathrm{C}$; after $48 \mathrm{~h}$, the solution was replaced. When $80 \%$ cells were fused, they were digested using $0.25 \%$ trypsin, followed by passage as the $\mathrm{P} 1$ generation. P3-P5-generation ADSCs were used for experiments.

\section{Preparation of two kinds of dermal scaffolds}

Preparation of acellular dermal matrix (ADM). ADM was prepared using the traditional method $(6,7)$. Under aseptic conditions, the subcutaneous adipose tissues were cut off, placed into $1 \mathrm{~mol} / 1 \mathrm{NaCl}$ solution for thermostatic water bath at $37^{\circ} \mathrm{C}$ for $24 \mathrm{~h}$, repeatedly washed with PBS to remove the epidermal cells, placed into $2 \% \mathrm{NaOH}$ solution for thermostatic water bath at $37^{\circ} \mathrm{C}$ for $16 \mathrm{~h}$, and washed again with PBS repeatedly until the solution became neutral. Then tissues were placed at $-80^{\circ} \mathrm{C}$ for $4 \mathrm{~h}$, thawed in a thermostatic water bath box at $37^{\circ} \mathrm{C}$ for $4 \mathrm{~h}$; the freezing-thawing process was repeated 4 times. Finally, tissues were washed with PBS repeatedly, and stored at $4^{\circ} \mathrm{C}$ for standby application after frozen drying.

Preparation of NCSS. Under aseptic conditions, the subcutaneous adipose tissues were cut off, placed into $1 \mathrm{~mol} / \mathrm{l}$ $\mathrm{NaCl}$ solution for thermostatic water bath at $37^{\circ} \mathrm{C}$ for $24 \mathrm{~h}$, repeatedly washed with $\mathrm{PBS}$ to remove the epidermal cells, treated with $2 \% \mathrm{NaOH}$ solution on a shaker at $45^{\circ} \mathrm{C}$ for $4 \mathrm{~h}$, and washed again with PBS repeatedly until the solution became neutral. Then tissues were placed at $-80^{\circ} \mathrm{C}$ for $4 \mathrm{~h}$, thawed in a thermostatic water bath box at $37^{\circ} \mathrm{C}$ for $4 \mathrm{~h}$; the freezingthawing process was repeated for 4 times. Finally, tissues were washed with PBS repeatedly, and stored at $4^{\circ} \mathrm{C}$ for standby application after frozen drying.

ADM and NCSS were hematoxylin and eosin (H\&E) stained and observed under a scanning electron microscope (SEM).

Construction and cytocompatibility of tissue-engineered skin. P3-generation ADSCs were inoculated into a 24-well plate ( $2 \times 10^{5} /$ well), placed on NCSS soaked in complete medium in advance for $48 \mathrm{~h}$, and incubated under saturated humidity with $5 \% \mathrm{CO}_{2}$ at $37^{\circ} \mathrm{C}$ for 3 and 7 days, followed by fixation via formalin and $\mathrm{H} \& \mathrm{E}$ staining.

Wound model establishment and grouping of nude mice. After 24 nude mice were weighed and anesthetized intraperitoneally with $10 \%$ chloral hydrate $(300 \mathrm{mg} / \mathrm{kg})$, two $10 \mathrm{~mm}^{2}$ round full-thickness skin defects were designed on both sides of the back reaching the subcutaneous fascia; the defect borders were fixed with 6-0 suture. Mice were randomly divided into 4 groups: ADSCs-NCSS (group A, cultured for 7 days), simple NCSS (group B), simple ADSCs (group C) and blank control (group D, simply covered with oil gauze). After operation, all wounds were treated with pressure dressing, and mice were fed in separate cages.

Specimen collection and detection. At 3, 7, 10 and 14 days, the wounds were opened, photographed and re-bandaged, and the wound healing rate was calculated (Image-Pro Plus software; Media Cybernetics, Inc., Rockville, MD, USA). At 7 and 14 days after operation, 12 nude mice were sacrificed by cervical dislocation, and the skin tissues were cut at $2 \mathrm{~mm}$ outside the normal skin along the wound margin reaching the muscular layer. After fixation via formalin, embedding and sectioning, skin tissues received $\mathrm{H} \& \mathrm{E}$ and immunohistochemical assay to detect the regenerated tissue thickness and vascular density (Image-Pro Plus software). Wound healing rate $=$ (original wound area - residual wound area)/original wound area $\mathrm{x} 100 \%$. Regenerated tissue thickness: H\&E-stained sections were taken to detect the regenerated tissue thickness in each group under a microscope (x200), excluding the regenerated epidermal cells; five points were selected from each section at the same interval of distance for measurement. Vascular density detection: Immunohistochemical sections were taken to count the cluster of differentiation 31 (CD31)-positive blood vessels under a microscope (x200). Deep brown-stained cells, instead of the formation of lumen or the presence or absence of red blood cells in the lumen, could be regarded as one counting unit. Four different fields of view were selected from each section to calculate the average number of blood vessels per unit field of view, namely the interstitial microvessel density.

Statistical processing. Experimental data were analyzed and processed using Statistical Product and Service Solutions (SPSS) 12.0 software. Data were presented as mean \pm SD. One-way analysis of variance was used for the pairwise comparison among groups and the post hoc test was Least Significant Difference test. The results are presented as P-value $(\alpha=0.05) . P<0.05$ was considered to indicate a statistically significant difference. 

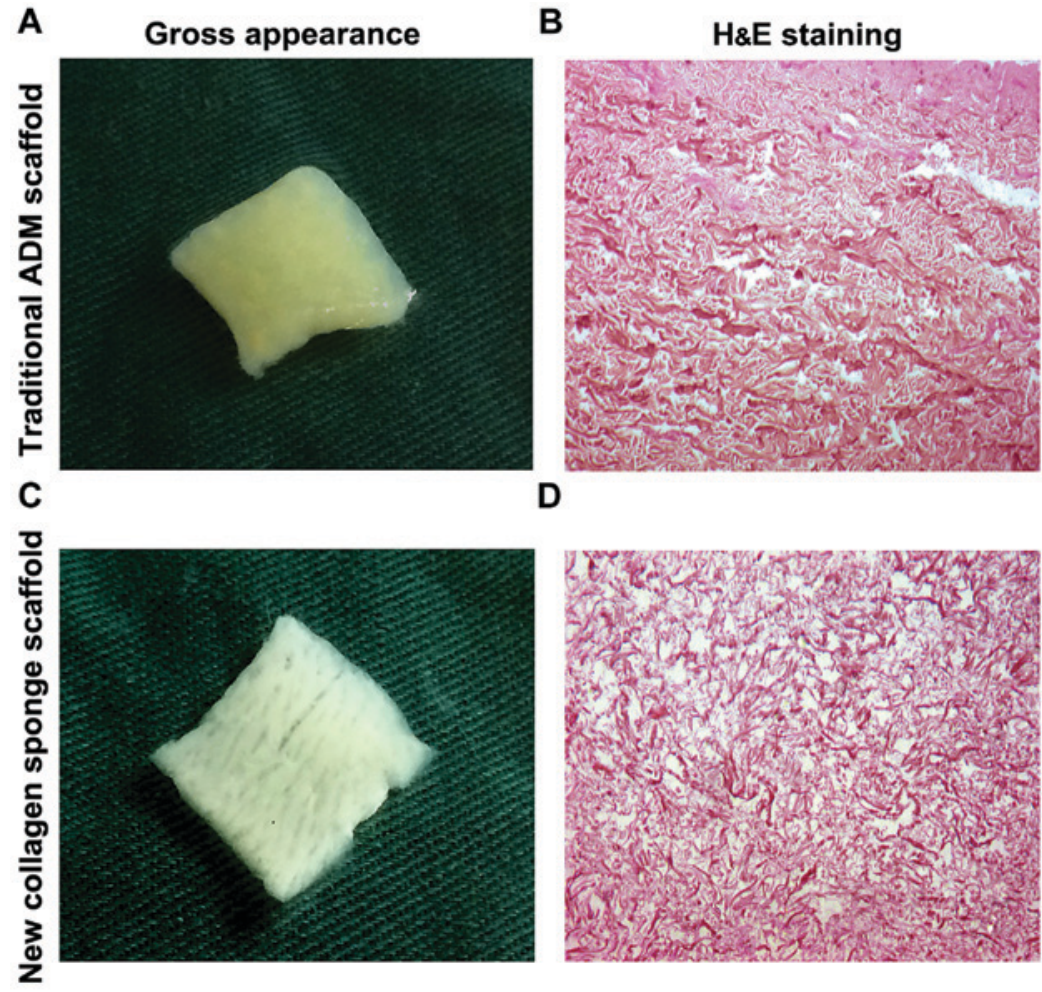

Figure 1. General and H\&E staining observation of scaffold materials. (A) Traditional ADM scaffold is milky white or light yellow, and its surface is smooth and dense. (B) H\&E staining results of traditional ADM scaffold show the red-stained coarse collagen with uniform porosity (x100). (C) NCSS is milky white, soft and loose. (D) NCSS shows loose structure of collagen fibers and slender fibers (x100). ADM, acellular dermal matrix; NCSS, new collagen sponge scaffold.

\section{Results}

Detection of scaffold material characteristics

Morphological observation of two kinds of scaffold materials. By naked eye, traditional ADM scaffold was milky white or light yellow, tough texture, the surface was flat, smooth and flexible, and the dense hair follicle holes could be observed (Fig. 1A); NCSS was milky white or light yellow, showing soft, loose porous homogeneous shape, and the surface loose pores could be clearly observed (Fig. 1C).

Histological observation (H\&E staining) of two kinds of scaffold materials. After H\&E staining, traditional ADM scaffold showed red-stained coarse collagen, orderly arrangement of collagen fibers, complete fibers and uniform pores (Fig. 1B); NCSS showed loose collagen fibers, slender fibers, complete structure of collagen fibers and uniform pore distribution (Fig. 1D).

Comparison of pore size of two kinds of scaffold materials under SEM. No cellular composition could be seen on the surface of two kinds of scaffold materials under SEM, and the collagen fibers were arranged neatly and distributed evenly. The fibers were more slender in NCSS than those in traditional ADM scaffold, and the porosity was also higher than that in traditional ADM scaffold by naked eye (Fig. 2).

Cytocompatibility and permeability of two kinds of scaffold materials. At 3 and 7 days after P4-generation ADSCs were inoculated onto the traditional ADM scaffold material, H\&E staining showed that cells grew in the form of single layer on the surface of scaffold basement membrane, the number of cells was increased significantly with the passage of time, and there was no significant intradermal infiltration (Fig. 3A and B). At 3 and 7 days after ADSCs were inoculated onto NCSS, H\&E staining showed that stem cells could break through the basal layer for infiltrative growth; the cell infiltration depth at 7 days was significantly increased compared with that at 3 days, and the number of cells was also obviously increased (Fig. 3C and D).

\section{Skin defect repair via ADSCs combined with NCSS}

Wound changes and wound healing rate. At 3 days after operation, the wound was opened; the grafted skin in groups A and B was ruddy with fine blood supply; the wounds in groups $\mathrm{C}$ and $\mathrm{D}$ were clean and moist with fresh granulation tissues. At 7 days after operation, the wounds in groups A and B were significantly reduced, and the grafted skin surfaces were partially desquamated, which was more obvious in group B than group $\mathrm{A}$; the wounds in groups $\mathrm{C}$ and $\mathrm{D}$ were further reduced, and there were no necrosis or infection in either group. At 10 days after operation, the wound in group A was mostly healed, and the wound areas in other groups were significantly reduced. At 14 days after operation, the wound in group A was basically healed, and the residual areas were larger in other groups (Fig. 4). There were no significant differences in the wound healing rate among groups A-D at 3 days $(\mathrm{p}>0.05)$. At 7, 10 and 14 days, the wound healing rates in group A were significantly better than those in groups B-D, and the differences were statistically significant $(\mathrm{p}<0.05)$; the differences among groups B-D were not statistically significant $(\mathrm{p}>0.05$; Table I). 
A

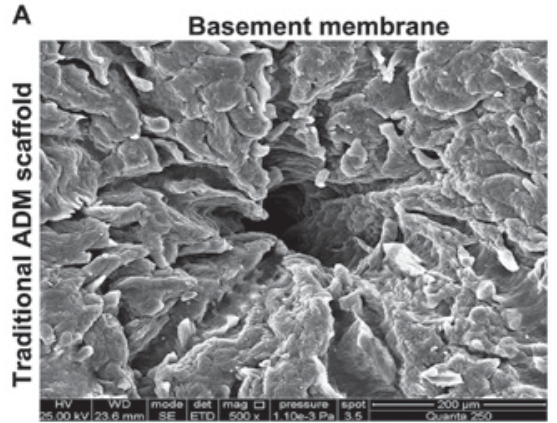

C

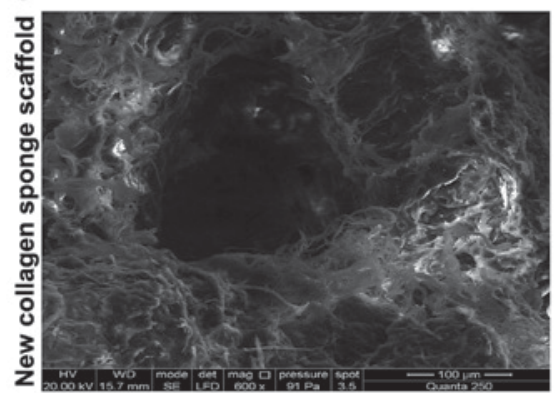

B
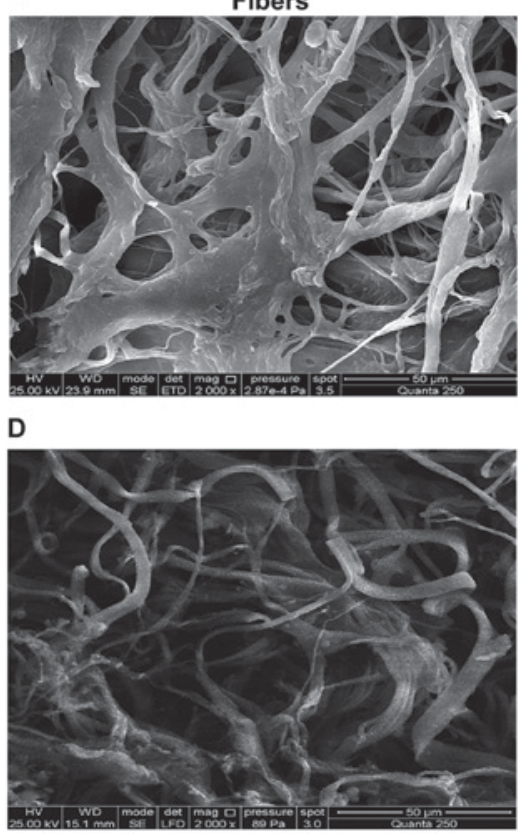

Figure 2. Detection of cavity diameters of the two kinds of scaffolds. SEM results: (A) The surface porosity of basement membrane of traditional ADM scaffold is low, and the pore size is also low (x500). (B) The traditional ADM scaffold has complete and coarse fibers (x2,000). (C) The fibers of basement membrane of NCSS are slender with high porosity (x600). (D) NCSS has complete and slender fibers. ADM, acellular dermal matrix; NCSS, new collagen sponge scaffold.

A
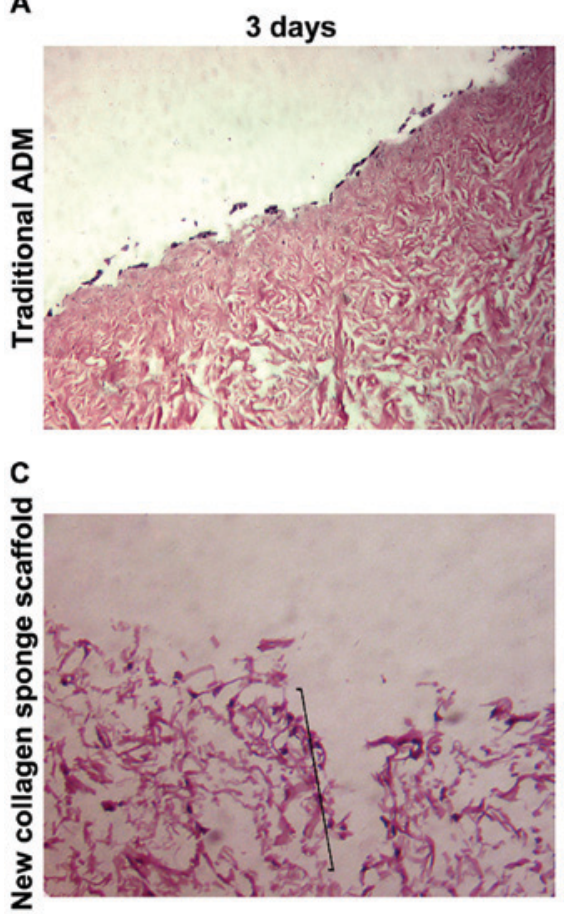

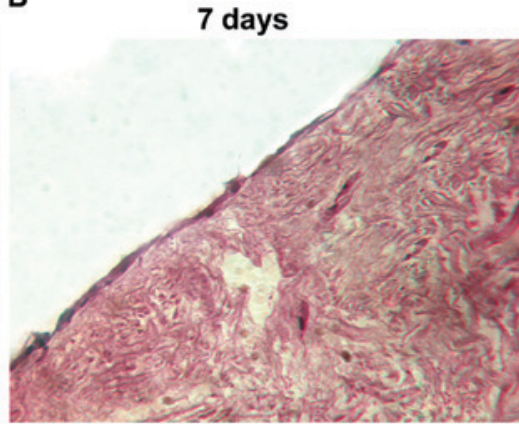

D

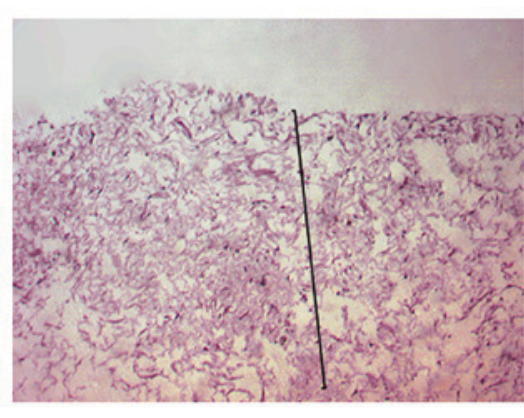

Figure 3. (A) Cells grow on the surface of scaffold in the form of single layer at 3 days after traditional ADM combined with stem cells (x100). (B) Cells grow on the surface of scaffold in the form of single-multiple layer at 7 days after traditional ADM combined with stem cells (x100). (C) Cells show infiltrative growth at 3 days after NCSS combined with stem cells (x100). (D) The depth of cell infiltration is increased at 7 days after NCSS combined with stem cells (x50). The black lines in C and D represent the depth of infiltration. ADM, acellular dermal matrix; NCSS, new collagen sponge scaffold.

Histological observation of regenerated skin. At 7 days after operation, the wound tissues were treated with H\&E staining, and observed under an inverted phase contrast microscope. Results showed the granulation tissue proliferation in wounds in groups A-D, accompanied by a large number of microvessels, and varying degrees of inflammatory cell infiltration in regenerated tissues, accompanied by epidermal cell regeneration in different degrees (Fig. 5). The thickness of regenerated tissues was $(222.72 \pm 29.37 \mu \mathrm{m})$ in group A, $(180.80 \pm 10.32 \mu \mathrm{m})$ in group B, $(194.18 \pm 5.85 \mu \mathrm{m})$ in group C 
A
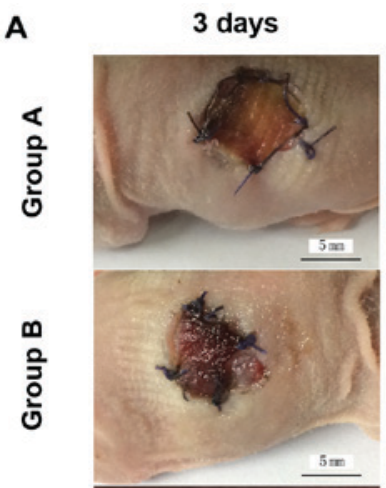

0
0
0
0
0
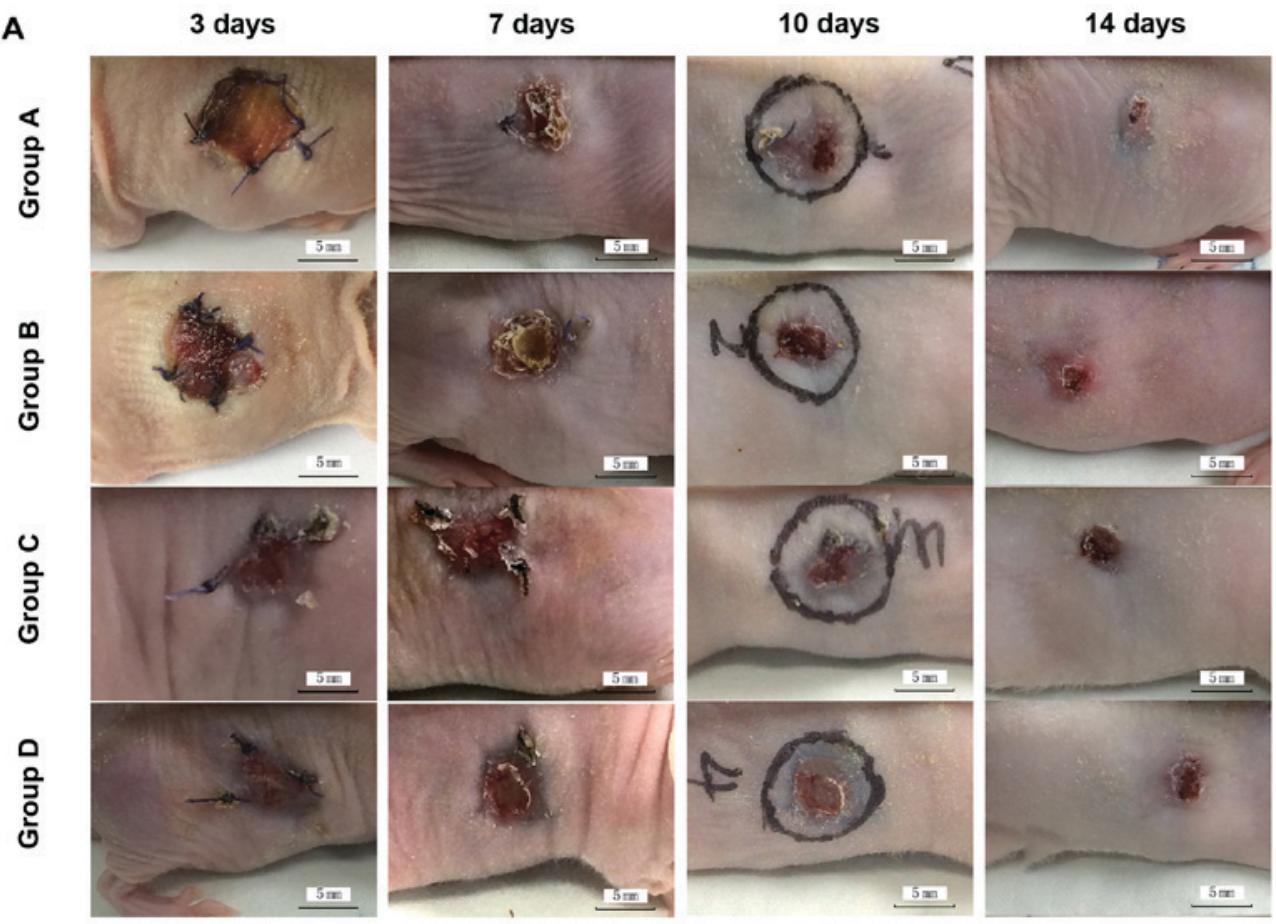

B

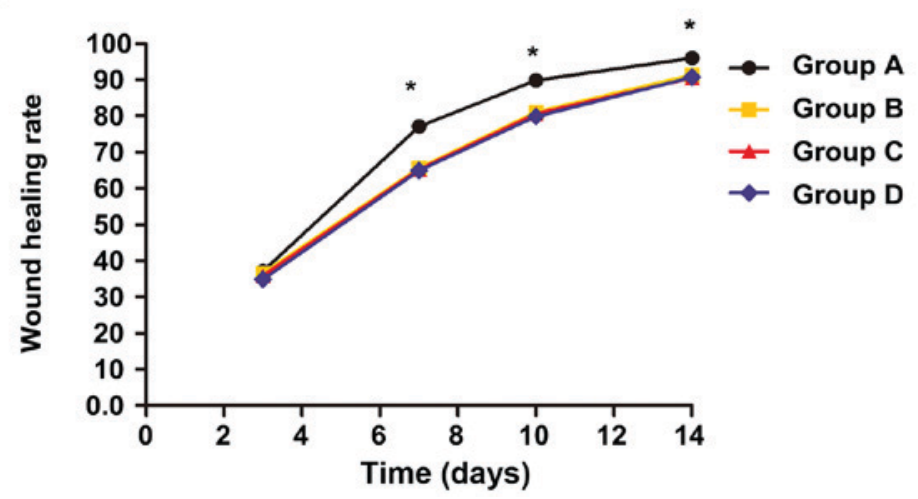

Figure 4. (A) Wounds at different time-points in each group. (B) There are no statistically significant differences in the pairwise comparisons of wound healing rate among groups at 3 days after operation ( $\mathrm{p}>0.05$ ); at 7, 10 and 14 days after operation, there are significant differences in groups B-D compared with group A ( $\left.{ }^{\mathrm{p}}<0.05\right)$; there are no statistically significant differences in the wound healing rate among groups B-D (p>0.05) (Fig. 1B). Group A, ADSCs-NCSS group; group B, simple NCSS group; group C, simple ADSCs group; and group D, blank control group. ADSCs, adipose-derived stem cells; NCSS, new collagen sponge scaffold.

and $(175.94 \pm 25.79 \mu \mathrm{m})$ in group D. The thickness of regenerated tissues in group A was significantly larger than those in groups B-D, and the differences were statistically significant $(p<0.05)$; there were no statistically significant differences among groups B-D ( $>0.05)$.

Immunohistochemical detection. At 7 days after operation, the wound tissues were taken, fixed and sectioned. The immunohistochemical detection showed that the number of new vessels (deep brown-stained) in the wound in each group was larger than that at 14 days. At 14 days after operation, most vessels were occluded, and the number of vessels was decreased. At 7 days after operation, the average vascular densities in groups A-D were 7.0 \pm 1.2 , $3.8 \pm 1.7,4.5 \pm 1.0$ and $4.3 \pm 1.5$, respectively. The vascular density in group A was obviously larger than those in groups B-D, and the difference was statistically significant
Table I. Wound healing rate at each time-point after operation.

\begin{tabular}{lcccc}
\hline & \multicolumn{5}{c}{ Wound healing rate (\%) } \\
\cline { 2 - 5 } Groups & 3 days & 7 days & 10 days & 14 days \\
\hline A & $37.16 \pm 0.78$ & $77.13 \pm 1.25$ & $89.90 \pm 1.08$ & $96.08 \pm 0.6$ \\
B & $36.64 \pm 1.02$ & $65.74 \pm 1.31$ & $81.09 \pm 0.83$ & $91.39 \pm 0.92$ \\
C & $35.96 \pm 1.78$ & $65.26 \pm 0.84$ & $80.59 \pm 0.94$ & $90.55 \pm 0.78$ \\
D & $34.91 \pm 1.58$ & $64.96 \pm 1.21$ & $79.86 \pm 1.42$ & $90.68 \pm 0.53$
\end{tabular}

$(p<0.01)$; there were no statistically significant differences among groups B-D $(p>0.05)$. At 14 days after operation, immunohistochemical detection showed that the average 

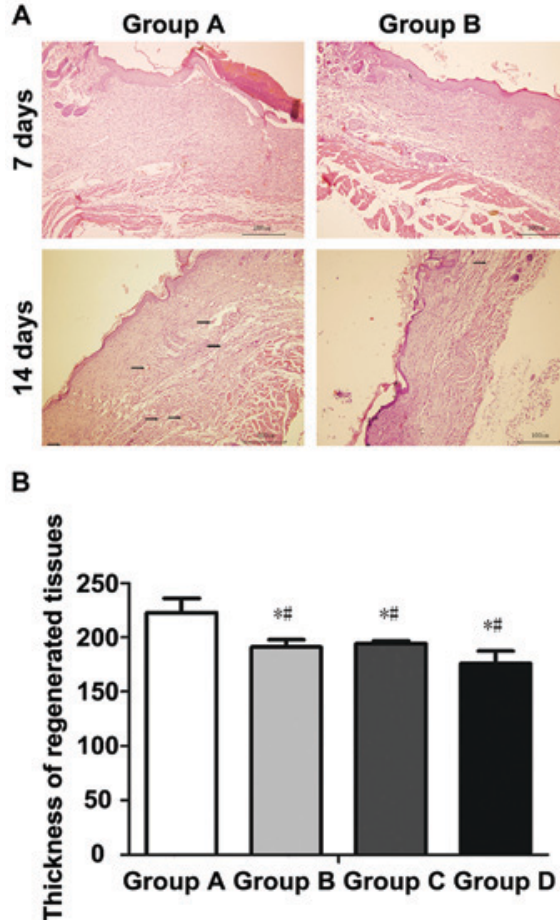

Group B
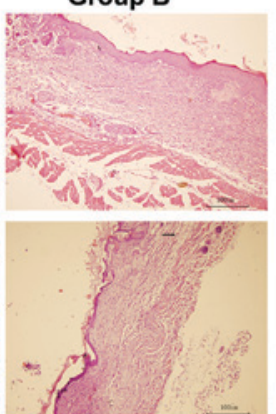

C

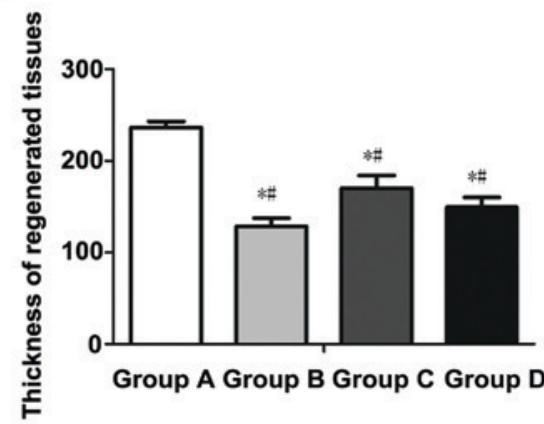

Figure 5. Histological and thickness detection of regenerated tissues at 7 and 14 days after operation. (A) Histological detection of regenerated tissues at 7 and 14 days after operation; (B) compared with group A, the thickness detection difference of regenerated tissues at 7 days after operation between groups B-D was statistically significant $(" \mathrm{p}<0.05)$. The difference between groups B-D was not statistically significant $(\# \mathrm{p}>0.05)$. (C) compared with group A, the thickness detection difference of regenerated tissues at 4 days after operation in group B-D was statistically significant ( $" \mathrm{p}<0.05)$. The difference between groups B-D was not statistically significant $\left({ }^{\#} \mathrm{p}>0.05\right)$. The black arrows indicate regenerated blood vessel. Group A, ADSCs-NCSS group; group B, simple NCSS group; group C, simple ADSCs group; and group D, blank control group.

A

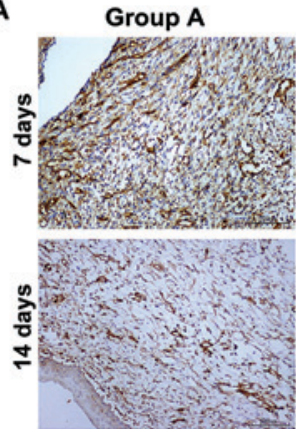

B

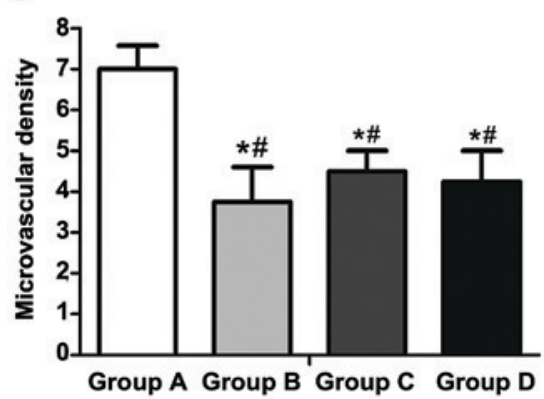

Group B
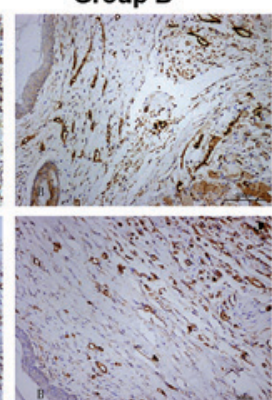

C

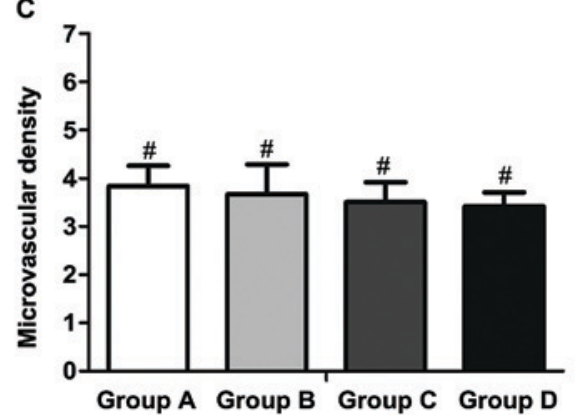

Figure 6. CD31 immunohistochemical detection and microvascular density of regenerated tissues at 7 and 14 days after operation. (A) ADSCs-NCSS (group A), simple NCSS (group B), simple ADSCs (group C) and blank control (group D). (B) At 7 days after operation, there are statistically significant differences in groups B-D compared with group A ( $\left.{ }^{*} \mathrm{p}<0.05\right)$; there are no statistically signifcant differences among groups B-D ( $\left.{ }^{\#} \mathrm{p}>0.05\right)$. (C) At 14 days after operation, there are no statistically significant differences among groups A-D $\left({ }^{\sharp} \mathrm{p}<0.05\right)$. Group A, ADSCs-NCSS group; group B, simple NCSS group; group C, simple ADSCs group; group D, blank control group.

vascular densities in groups A-D were $3.8 \pm 1.5,3.6 \pm 2.1$, $3.5 \pm 1.4$ and $3.4 \pm 0.9$, respectively; there were no statistically significant differences in the comparison of vascular density among groups ( $\mathrm{p}>0.05$ ) (Fig. 6A-C). 


\section{Discussion}

The large-area wounds left after severe burn, chronic ulcer and resection of huge superficial tumor often have significant impact on the patient's physiology and psychology. Currently, the ideal treatment method is the autologous split-thickness and full-thickness skin grafting; however, patients with large-area skin defects often have problems such as insufficient autologous skin source, new auxiliary incision left during operation, increase of several surgical scars (8), seriously affecting the clinical treatment and prognosis of patients. The development of tissue engineering technique provides a promising treatment means for wound repair. Moreover, the selection of seed cells and scaffold materials is crucial in the construction of tissue-engineered skin.

Experimental studies have shown that ADSCs can regulate the regenerative microenvironment, and secrete the wound healing factors during wound repair process (8-10); at the same time, they also have anti-inflammatory and immunosuppressive effects $(11,12)$, with the advantages of promoting cell proliferation, migration, angiogenesis, anti-apoptosis, improving scar healing (13-16). ADSCs, therefore, have become a hot topic in the tissue engineering research.

It was found in the study on stem cells in wound repair that how to effectively transport stem cells, making them further differentiate and proliferate in the target area and exert the repairing effect, is also a difficulty $(17,18)$. Simple injection of stem cell suspension easily leads to the 'island'-like deposition of wound cells, local wound ischemia and hypoxia-induced cell necrosis; besides, the injection scope of stem cell suspension cannot be precisely controlled, wounds are unevenly distributed, and a large number of cells are lost (19), affecting the stem cell suspension injection effect in wound repair. Thus, it can be seen that reducing the cell loss and death during the migration process and increasing the effective survival rate in transplantation process are extremely important for wound repair. Therefore, a suitable stem cell transfer vector will play an important role in wound repair.

Scaffold materials can provide stem cells with adhesion, growth and proliferation sites, and carry sufficient number of seed cells required for wound repair as stem cell transport vectors. The collagen scaffold provides the cell adhesion site for stem cells during wound repair, which facilitates the cell adhesion, proliferation and migration and provides a good microenvironment for cell growth; moreover, it can completely cover and protect the wounds, and prevent the exogenous bacterial infection. It was found in previous studies that ADM prepared using the traditional method has problems of low porosity, non-penetrating pore and poor cell permeability, resulting in low cell utilization rate and few adherent cells. It is currently believed that the ideal dermal scaffold material should possess higher porosity, larger pore size, good cell and tissue compatibility, and biodegradability. High porosity and larger pore size are the prerequisites for rapid vascularization in the wound, while the early rapid vascularization is the key to good wound healing.

During the preparation of dermal scaffolds, it was found that temperature has a significant effect on collagen structure. When heated, collagen fibers will have irreversible shrinkage; when the temperature rises to $63-65^{\circ} \mathrm{C}$, the fiber length will become $1 / 9$ of the original one; if heated continuously, the triple-helical structure of collagen molecules will be destroyed, denatured and decomposed into gelatin, thus losing the natural pores among collagen fibers and its scaffold effect. Sun et al (20) found through the second-harmonic microscope that thermal denaturation may occur in collagen at $54^{\circ} \mathrm{C}$. After repeated experiments, $45^{\circ} \mathrm{C}$ was selected as a controllable condition for the preparation of scaffold materials, which can shorten the length of collagen and loosen the pore structure of collagen without changing the three-dimensional structure of collagen and leading to collagen denaturation. Besides, alkaline process control also has a more obvious impact on dermal collagen fiber structure; under certain conditions, the collagen fibers become increasingly looser with the increase of alkaline solution concentration. Therefore, the temperature and alkali solution in a certain concentration were used as two treatment factors, and changing the treatment time as the experimental condition to successfully prepare NCSS via repeated experiments. The experimental results showed that the porosity of NCSS prepared using the modified method $(93.1 \pm 1.02 \%)$ was significantly higher than that of conventional ADM scaffold (74.27 $\pm 2.04 \%$ ), and the diameter of cavity was (40-247 $\mu \mathrm{m})$. There was no statistically significant difference in the in vitro degradation time between the two kinds of scaffold materials, basically meeting the requirement for rapid vascularization of artificial dermis.

The collagen scaffold prepared in this experiment had obvious three-dimensional structure, which was conducive to the cell adhesion, growth and proliferation; the diameter of biological pores was large, benefiting the cell infiltrative growth; the cell adhesion rate and migration efficiency were high without obvious cytotoxicity, but a certain mechanical strength and good plasticity; it could also completely cover the wound and prevent cell infection. After the repair of fullthickness skin defect on the back of nude mice via ADSCs combined with NCSS, the wound healing rate was significantly higher than those in other groups, indicating that the new tissue-engineered skin substitute constructed can significantly promote wound healing. Results of H\&E staining showed that the regenerated tissues of wound were atrophic and thinner at 14 days compared with those at 7 days, the vascular lumen was occluded and the number of vessels was also decreased. At 7 and 14 days, the thickness of regenerated tissues in group A was significantly larger than those in groups B-D. The number of immunohistochemical CD31-positive vessels in group A at 7 days after operation was significantly larger than those in groups B-D, suggesting that ADSCs combined with NCSS can significantly promote wound repair and angiogenesis, and increase the vascular density in the early stage of wound repair.

ADSCs combined with NCSS and the specific mechanism of ADSCs in wound healing were not studied in this experiment, but the animal experimental results showed that the wound healing rate, regenerated tissue thickness and vascular density in group A were higher than those in other experimental control and blank control groups, which was consistent with the results of literature $(7,10,15,21,22)$; at the same time, the initial purpose of this experimental research was achieved.

The key to wound healing is the early vascularization (23). In this study, the tissue-engineered skin substitute was constructed using ADSCs combined with NCSS. After operation, the 
wound was photographed and taken for histological detection and immunohistochemical CD31 vascular density detection. Results showed that the new tissue-engineered skin substitute could increase the vascular density in the wound, and improve the wound healing rate.

NCSS prepared during the experiment met the basic requirements of scaffold materials in tissue-engineered skin construction to a certain extent. The tissue-engineered skin substitute constructed also met the basic conditions of wound repair, and its biological property, mechanical strength and other aspects remain to be studied in subsequent experiments.

\section{Acknowledgements}

Not applicable.

\section{Funding}

No funding was received.

\section{Availability of data and materials}

The datasets used and/or analyzed during the present study are available from the corresponding author on reasonable request.

\section{Authors' contributions}

AJZ contributed to specimen collection and detection. TJ and QL helped with preparation of two kinds of dermal scaffolds. PSJ and QT were responsible for wound model establishment of mice. All authors read and approved the final manuscript.

\section{Ethics approval and consent to participate}

Patients aged 23-45 years signed the informed consent, those with infectious or skin lesions were excluded, and this study was approved by the Ethics Committee of the Drum Tower Clinical College of Nanjing Medical University (Nanjing, China).

\section{Patient consent for publication}

Not applicable.

\section{Competing interests}

The authors declare that they have no competing interests.

\section{References}

1. Shingyochi Y, Orbay H and Mizuno H: Adipose-derived stem cells for wound repair and regeneration. Expert Opin Biol Ther 15: 1285-1292, 2015.

2. Ozpur MA, Guneren E, Canter HI, Karaaltin MV, Ovali E, Yogun FN, Baygol EG and Kaplan S: Generation of skin tissue using adipose tissue-derived stem cells. Plast Reconstr Surg 137: 134-143, 2016.

3. Orbay H, Takami Y, Hyakusoku H and Mizuno H: Acellular dermal matrix seeded with adipose-derived stem cells as a subcutaneous implant. Aesthetic Plast Surg 35: 756-763, 2011.

4. Kim HJ, Park SS, Oh SY, Kim H, Kweon OK, Woo HM and Kim WH: Effect of acellular dermal matrix as a delivery carrier of adipose-derived mesenchymal stem cells on bone regeneration. J Biomed Mater Res B Appl Biomater 100: 1645-1653, 2012.
5. Zuk PA, Zhu M, Ashjian P, De Ugarte DA, Huang JI, Mizuno H, Alfonso ZC, Fraser JK, Benhaim P and Hedrick MH: Human adipose tissue is a source of multipotent stem cells. Mol Biol Cell 13: 4279-4295, 2002

6. Zhang X, Deng Z, Wang H, Yang Z, Guo W, Li Y, Ma D, Yu C, Zhang $\mathrm{Y}$ and Jin Y: Expansion and delivery of human fibroblasts on micronized acellular dermal matrix for skin regeneration. Biomaterials 30: 2666-2674, 2009.

7. Huang SP, Hsu CC, Chang SC, Wang CH, Deng SC, Dai NT, Chen TM, Chan JY, Chen SG and Huang SM: Adipose-derived stem cells seeded on acellular dermal matrix grafts enhance wound healing in a murine model of a full-thickness defect. Ann Plast Surg 69: 656-662, 2012.

8. Wendt H, Hillmer A, Reimers K, Kuhbier JW, Schäfer-Nolte F, Allmeling C, Kasper C and Vogt PM: Artificial skin - culturing of different skin cell lines for generating an artificial skin substitute on cross-weaved spider silk fibres. PLoS One 6: e21833, 2011.

9. Reagan MR and Kaplan DL: Concise review: Mesenchymal stem cell tumor-homing: Detection methods in disease model systems. Stem Cells 29: 920-927, 2011.

10. Anthony DF and Shiels PG: Exploiting paracrine mechanisms of tissue regeneration to repair damaged organs. Transplant Res 2: $10,2013$.

11. Singer NG and Caplan AI: Mesenchymal stem cells: Mechanisms of inflammation. Annu Rev Pathol 6: 457-478, 2011.

12. Liu L, Chiu PW, Lam PK, Poon CC, Lam CC, Ng EK and Lai PB: Effect of local injection of mesenchymal stem cells on healing of sutured gastric perforation in an experimental model. Br J Surg 102: e158-e168, 2015.

13. Maxson S, Lopez EA, Yoo D, Danilkovitch-Miagkova A and Leroux MA: Concise review: Role of mesenchymal stem cells in wound repair. Stem Cells Transl Med 1: 142-149, 2012.

14. Liu YL, Liu WH, Sun J, Hou TJ, Liu YM, Liu HR, Luo YH, Zhao NN, Tang Y and Deng FM: Mesenchymal stem cell-mediated suppression of hypertrophic scarring is $\mathrm{p} 53$ dependent in a rabbit ear model. Stem Cell Res Ther 5: 136, 2014.

15. Wahl EA, Fierro FA, Peavy TR, Hopfner U, Dye JF, Machens HG, Egaña JT and Schenck TL: In vitro evaluation of scaffolds for the delivery of mesenchymal stem cells to wounds. BioMed Res Int 2015: 108571, 2015.

16. Harasymiak-Krzyżanowska I, Niedojadło A, Karwat J, Kotuła L, Gil-Kulik P, Sawiuk M and Kocki J: Adipose tissue-derived stem cells show considerable promise for regenerative medicine applications. Cell Mol Biol Lett 18: 479-493, 2013.

17. Kuo YR, Wang CT, Cheng JT, Kao GS, Chiang YC and Wang CJ: Adipose-derived stem cells accelerate diabetic wound healing through the induction of autocrine and paracrine effects. Cell Transplant 25: 71-81, 2016.

18. Hiwatashi N, Hirano S, Mizuta M, Tateya I, Kanemaru S, Nakamura T and Ito J: Adipose-derived stem cells versus bone marrow-derived stem cells for vocal fold regeneration. Laryngoscope 124: E461-E469, 2014.

19. Yang J, Yamato M, Kohno C, Nishimoto A, Sekine H, Fukai F and Okano T: Cell sheet engineering: Recreating tissues without biodegradable scaffolds. Biomaterials 26: 6415-6422, 2005.

20. Sun Y, Chen WL, Lin SJ, Jee SH, Chen YF, Lin LC, So PT and Dong CY: Investigating mechanisms of collagen thermal denaturation by high resolution second-harmonic generation imaging. Biophys J 91: 2620-2625, 2006.

21. Leonardi D, Oberdoerfer D, Fernandes MC, Meurer RT, Pereira-Filho GA, Cruz P, Vargas M, Chem RC, Camassola M, Nardi NB, et al: Mesenchymal stem cells combined with an artificial dermal substitute improve repair in full-thickness skin wounds. Burns 38: 1143-1150, 2012.

22. Iyyanki TS, Dunne LW, Zhang Q, Hubenak J, Turza KC and Butler CE: Adipose-derived stem-cell-seeded non-cross-linked porcine acellular dermal matrix increases cellular infiltration, vascular infiltration, and mechanical strength of ventral hernia repairs. Tissue Eng Part A 21: 475-485, 2015.

23. King A, Balaji S, Keswani SG and Crombleholme TM: The role of stem cells in wound angiogenesis. Adv Wound Care (New Rochelle) 3: 614-625, 2014.

This work is licensed under a Creative Commons Attribution-NonCommercial-NoDerivatives 4.0 International (CC BY-NC-ND 4.0) License. 